\title{
Article \\ Short Digital Spatial Memory Test Detects Impairment in Alzheimer's Disease and Mild Cognitive Impairment
}

\author{
Jackie M. Poos ${ }^{1,2,3, *(\mathbb{D}}$, Ineke J. M. van der Ham ${ }^{4}{ }^{(}$, Anna E. Leeuwis ${ }^{1}$, Yolande A. L. Pijnenburg ${ }^{1}$, \\ Wiesje M. van der Flier ${ }^{1,5}$ and Albert Postma ${ }^{3}$ \\ 1 Alzheimer Center Amsterdam, Department of Neurology, Amsterdam Neuroscience, Amsterdam University \\ Medical Center, Vrije Universiteit Amsterdam, 1007 MB Amsterdam, The Netherlands; \\ a.leeuwis@amsterdamumc.nl (A.E.L.); yal.pijnenburg@amsterdamumc.nl (Y.A.L.P.); \\ wm.vdflier@amsterdamumc.nl (W.M.v.d.F.) \\ 2 Department of Neurology, Erasmus MC University Medical Center, 3015 GD Rotterdam, The Netherlands \\ 3 Helmholtz Institute, Experimental Psychology, Utrecht University, 3584 CS Utrecht, The Netherlands; \\ a.postma@uu.nl \\ 4 Institute of Psychology, Health, Medical and Neuropsychology, Leiden University, \\ 2300 RB Leiden, The Netherlands; c.j.m.van.der.ham@fsw.leidenuniv.nl \\ 5 Department of Epidemiology \& Biostatistics, Vrije Universiteit Amsterdam, Amsterdam UMC, \\ 1081 HV Amsterdam, The Netherlands \\ * Correspondence: j.m.poos@erasmusmc.nl; Tel.: +31-253-3657
}

check for updates

Citation: Poos, J.M.; van der Ham, I.J.M.; Leeuwis, A.E.; Pijnenburg, Y.A.L.; van der Flier, W.M.; Postma, A. Short Digital Spatial Memory Test Detects Impairment in Alzheimer's Disease and Mild Cognitive Impairment. Brain Sci. 2021, 11, 1350. https://doi.org/10.3390/

brainsci11101350

Academic Editor: Tina Iachini

Received: 2 September 2021

Accepted: 9 October 2021

Published: 14 October 2021

Publisher's Note: MDPI stays neutral with regard to jurisdictional claims in published maps and institutional affiliations.

Copyright: (c) 2021 by the authors. Licensee MDPI, Basel, Switzerland. This article is an open access article distributed under the terms and conditions of the Creative Commons Attribution (CC BY) license (https:/ / creativecommons.org/licenses/by/ $4.0 /)$.
Abstract: Background: Impairment in navigation abilities and object location memory are often seen in early-stage Alzheimer's Disease (AD), yet these constructs are not included in standard neuropsychological assessment. We investigated the differential ability of a short digital spatial memory test in mild AD dementia and mild cognitive impairment (MCI). Methods: 21 patients with $\mathrm{AD}$ dementia $(66.9 \pm 6.9 ; 47 \%$ female), 22 patients with $\mathrm{MCI}(69.6 \pm 8.3 ; 46 \%$ female $)$ and 21 patients with subjective cognitive decline (SCD) $(62.2 \pm 8.9 ; 48 \%$ female) from the Amsterdam Dementia Cohort performed the Object Location Memory Test (OLMT), consisting of a visual perception and memory trial, and the Virtual Tübingen (VT) test, consisting of a scene recognition, route continuation, route ordering and distance comparison task. The correlations with other cognitive domains were examined. Results: Patients with mild AD dementia (Z: $-2.51 \pm 1.15)$ and $\mathrm{MCI}(\mathrm{Z}:-1.81 \pm 0.92)$ performed worse than participants with SCD (Z: $0.0 \pm 1.0)$ on the OLMT. Scene recognition and route continuation were equally impaired in patients with AD dementia $(Z:-1.14 \pm 0.73 ; Z:-1.44 \pm 1.13$ ) and MCI $(Z:-1.37 \pm 1.25 ; Z:-1.21 \pm 1.07)$. Route ordering was only impaired in patients with $\mathrm{MCI}(\mathrm{Z}:-0.82 \pm 0.78)$. Weak to moderate correlations were found between route continuation and memory $(\mathrm{r}(64)=0.40, p<0.01)$, and between route ordering and attention $(\mathrm{r}(64)=0.33, p<0.01)$, but not for the OLMT. Conclusion: A short digital spatial memory test battery was able to detect object location memory and navigation impairment in patients with mild AD dementia and MCI, highlighting the value of incorporating such a test battery in standard neuropsychological assessment.

Keywords: cognitive dysfunction; memory disorders; spatial navigation; neuropsychology; early diagnosis; dementia

\section{Introduction}

Alzheimer's disease (AD) is the most common form of dementia and is associated with marked impairment in episodic memory, and subsequent decline in executive functioning, language and visuospatial abilities [1]. The clinical stages of the AD pathological process include a preclinical stage, where subjective cognitive decline (SCD) may already be present [2], a prodromal stage that includes mild cognitive impairment (MCI) [3] and a symptomatic stage that is based on the severity of impairment and can be classified as mild, moderate and severe dementia [4]. The clinical diagnostic outcome measures to detect early stages of AD, including MCI, are currently strongly focused on verbal episodic 
memory tests [5], whereas the complaints of patients with AD dementia, in particular, often include wandering or getting lost while driving [6-9]. Given the frequency of spatial memory complaints in the early stages of AD dementia [6-9], proper evaluation of these processes is urgent but lacking in most standard diagnostic work-up settings.

Spatial memory consists of multiple visuospatial abilities that are a crucial part of our daily functioning. It involves the encoding, storage and retrieval of information about spatial layouts, which enables us to remember the positions of objects in place (object location memory) and to learn and remember routes (spatial navigation) [10]. Both processes have been shown to be related to atrophy of the hippocampus, the parahippocampal gyrus and parietal areas [11,12], areas that are known to show the first signs of neurodegeneration in $\mathrm{AD}$ [13]. Indeed, spatial memory impairment is not limited to patients with AD dementia, but can be detected earlier in patients with MCI [14].

However, currently, there are no comprehensive and ecologically valid tests available that are feasible for application in clinical settings [15]. Spatial memory processes such as object location memory and navigation are typically conducted in dynamic and complex environments, making it difficult to perform ecologically valid assessments in a clinical setting [16]. There are validated tabletop visuospatial tests such as the Mental Rotation Test [17], the Location Learning Test [18], the Corsi Block Tapping test [19] and the Money Road Map test [20]. However, these small-scale spatial tests are highly inflexible, measure only a single aspect in the spatial memory spectrum or have proven to be poor predictors of navigational abilities [21] and cognitive decline [22]. Other studies have aimed to simulate the complexity of real-life situations by assessing large-scale spatial navigation in real-world scenarios such as hospital settings (for example, [11,14,23-28]) or with innovative tests incorporating advanced virtual reality (VR) paradigms such as the Memory Island Test and the Sea Hero Quest $[14,25,26,29-38]$. Multiple studies have proven that real-world scenarios and VR applications appear to be more sensitive in identifying spatial navigation deficits in patients with $\mathrm{AD}$ in both the prodromal and symptomatic stage $[11,14,25,26,39-42]$. However, these experimental tests using real-world scenarios and/or VR applications are time-consuming (for example, most experimental tests take around 2-3 h to complete) and not feasible for clinical evaluation [15].

In light of this, the aim was to investigate the differential ability of a short digital test battery that is easy to administer and measures the most relevant aspects of spatial memory in a systematic and condensed, time-limited manner in patients with mild AD dementia and MCI. The Object Location memory Test (OLMT) is a computer program with which multiple crucial spatial memory processes such as spatial perception and construction, object and location memory, the binding of objects to locations and metric distance processing can easily be measured $[10,43]$. The test has been previously used and validated in healthy controls and stroke patients [10,43]. For spatial navigation, we used a virtual reality environment, the Virtual Tübingen (VT) task [12], including tasks to measure landmark recognition, location and path knowledge, in agreement with theories on navigation abilities $[12,44]$. We performed correlational analyses with six other neuropsychological cognitive domains to assess the relation between the spatial memory tests and well-known cognitive tests that are a part of the standard diagnostic work-up.

\section{Materials and Methods}

\subsection{Participants}

We recruited 21 patients with probable AD dementia, 22 patients with $\mathrm{MCI}$ and 21 participants with subjective cognitive decline (SCD) from the Amsterdam Dementia Cohort $[45,46]$. The diagnoses were established at a multidisciplinary consensus meeting of the Alzheimer Center Amsterdam, involving experienced neurologists, neuroradiologists, psychiatrists, neuropsychologists and a care consultant, according to established diagnostic criteria for MCI [3] and AD dementia [4]. Clinical diagnosis was based on a standardized clinical assessment consisting of a medical history, family history, physical examination, neuropsychological assessment, EEG and MR imaging of the brain [45,46], according to 
NIA-AA criteria [3,4]. Patients with other neurological/psychiatric diseases, traumatic brain injury and/or major vascular damage were excluded. Patients were labeled as having SCD when cognitive and laboratory investigations were normal compared to normative data and the criteria for MCI, dementia or any other neurological/psychiatric disorder known to cause cognitive complaints were not met. All patients received an information letter before their regular follow-up appointment and were recruited and tested directly afterwards. Exclusion criteria were $\leq 18$ on the Mini-Mental State Examination (MMSE) or $>1$ on the Clinical Dementia Rating scale (CDR), thereby excluding patients with moderate or severe AD dementia.

\subsection{Experimental Task Design and Procedure}

Participants were comfortably seated in a quiet room in front of a touchscreen monitor (19 inch) at a distance of $\pm 60 \mathrm{~cm}$. Data from the experiment were collected by registering touch presses on the monitor. The OLMT [47] consisted of four trials of which two were practice trials. The perception trial was to measure perceptual abilities, to control for possible perceptual impairments. Two $14.5 \times 14.5 \mathrm{~cm}$ squares were shown on a touchscreen monitor, with ten randomly placed objects in the left square. Each participant was given the following instruction: "You will see two square frames, with the left containing ten objects. On the right there is an empty square with ten identical objects on top. You have to reconstruct the object array in the right frame, making sure the positions match those in the left frame". For the memory trial, one $14.5 \mathrm{~cm}$ square was shown for $30 \mathrm{~s}$ with ten different objects. Participants were given the following instruction: "You will see a square containing objects for $30 \mathrm{~s}$. You have to remember the locations of these objects as accurately as possible. After the object disappear, you will see an empty square, and you have to relocate the objects to the correct locations". For the OLMT, absolute error rates and best-fit scores were calculated. The absolute error is the mean absolute distance in millimeters between the original and the relocated positions of the objects. For the best-fit score, all possible configurations between the original and the relocated positions were computed and the fit that had the smallest error rate was considered to be the best-fitting configuration [47]. In Figure 1, the perception and memory trial of the OLMT can be seen.

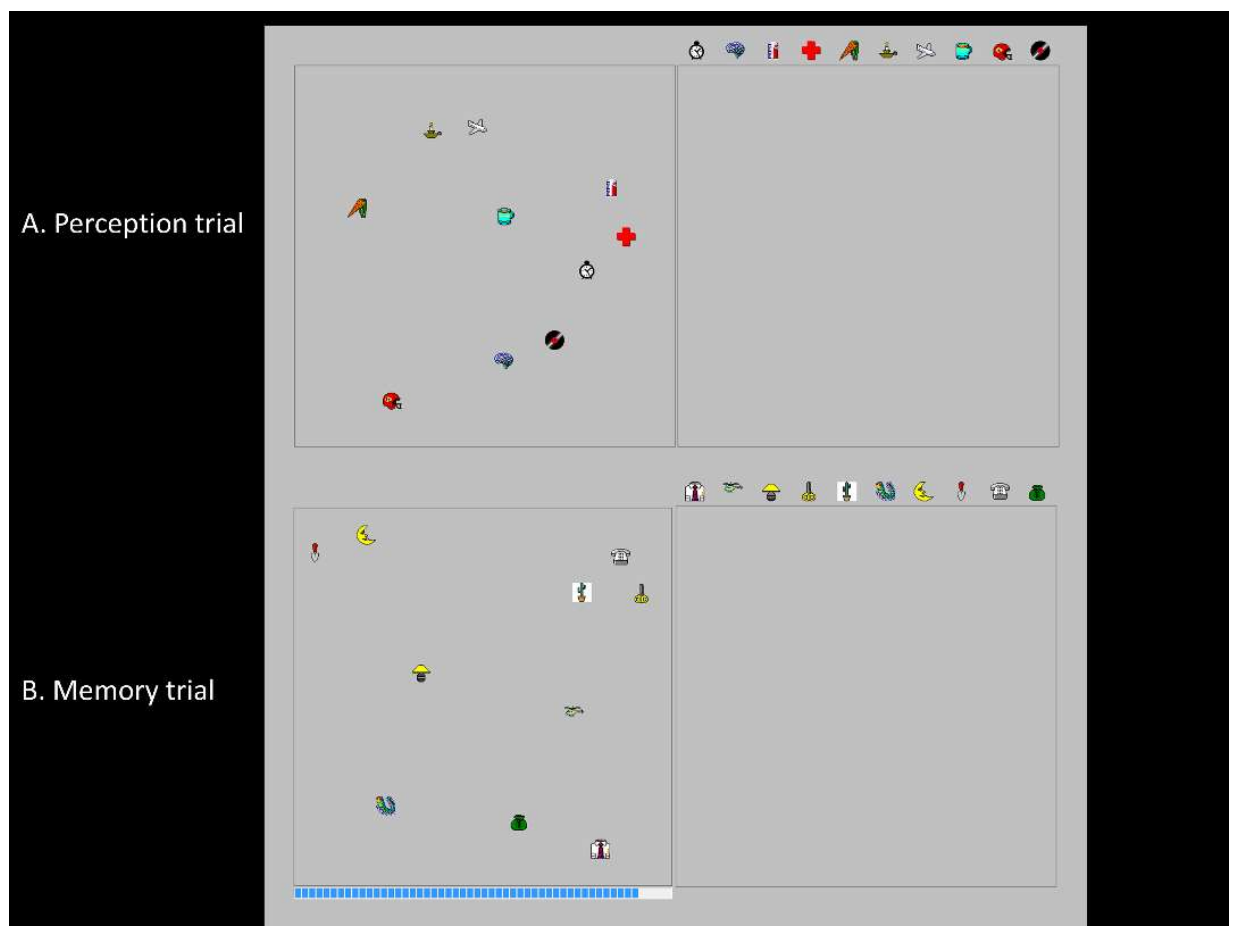

Figure 1. (A) the perception trial, and (B) the memory trial of the OLMT. 
The VT test [12] consisted of a study phase with a walking route in a virtual environment and four tests: scene recognition, route continuation, route ordering and distance comparison. Scene recognition was tested with twelve static images of which six were taken from the study phase movie, and six distractors. Route continuation involved six images from six crossing points on the route, where participants had to judge the direction the route continued in (left, straight, right). For route ordering, six images taken from the study phase movie had to be placed in the correct order. For the distance comparison test, participants had to judge the absolute distance between two pairs of images taken from the route and decide which distance is the shortest. For scene recognition, route continuation and distance comparison trials of the VT test, the number of correct answers was registered. For the route ordering trial, a temporal order score was calculated, where points were awarded when the temporal location of an item was higher than the direct antecedent of the item in the reconstructed order $(n-1)$. In total, the OLMT and VT test took 20 min to complete. In Figure 2, examples of the VT tasks can be seen.

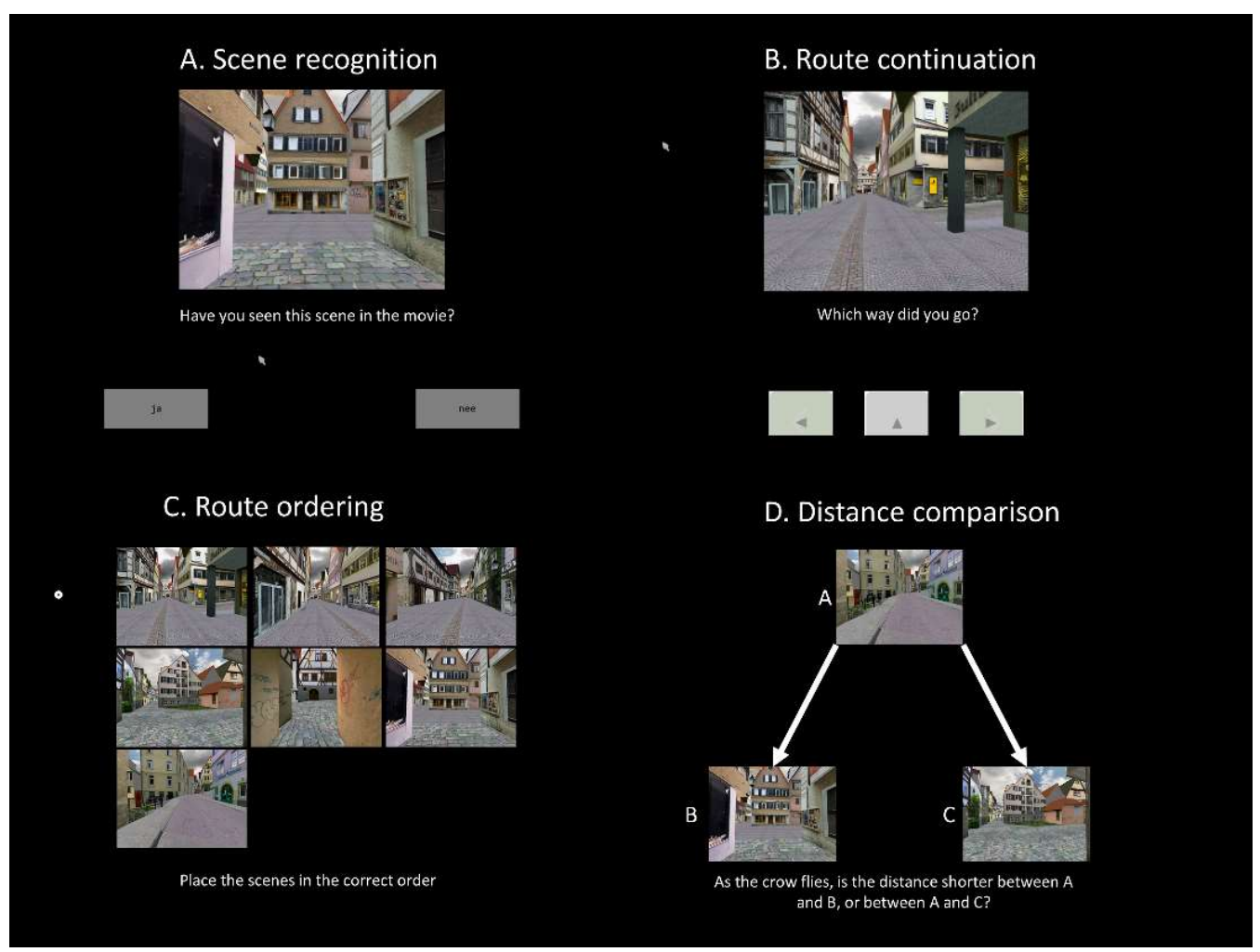

Figure 2. Examples of (A) the scene recognition, $(\mathbf{B})$ the route continuation, $(\mathbf{C})$ the route ordering and $(\mathbf{D})$ the distance comparison task.

\subsection{Standard Neuropsychological Test Battery}

Global cognitive functioning was screened by means of the Mini-Mental State Examination [48]. Experienced neuropsychologists administered neuropsychological tests within six cognitive domains: memory (Rey Auditory Verbal Learning Test (RAVLT)—Dutch version [49] and Visual Association Test (VAT) [50]), attention and mental processing speed (Trail Making Test (TMT)-A [51], Letter Digit Substitution Test (LDST) [52] and Digit Span forwards [53]), executive functioning (Digit Span backwards, TMT-B and phonological letter fluency [54]), language (VAT naming, categorical animal fluency [55]), visuospatial functioning (Number Location trial of the Visual Object and Space Perception (VOSP) [56] and apraxia (ideational and ideomotor)). 


\subsection{Data Analysis}

Statistical analyses were performed using SPSS Statistics 24.0 (IBM Corp., Armonk, NY, USA). We set the significance level at $p<0.05$ (2-tailed) across all comparisons, and used a Bonferroni correction for multiple comparisons. We compared demographic data between groups by means of one-way analyses. We analyzed differences in sex between groups using Pearson $\chi^{2}$ tests. For ease of interpretation, we normalized all raw test scores to the SCD group (i.e., individual test score minus the mean of the SCD group, divided by the $\mathrm{SD}$ of the SCD group). For the correlational analyses, we calculated domain scores based on the individual z-scores within that domain (see section "Standard neuropsychological test battery"). Due to non-normality of the data, a log transformation was applied to the raw test scores on the OLMT test. Four univariate analyses were performed with the log absolute error and log best-fit scores of the memory and perception trials as dependent variables, and group (i.e., $\mathrm{AD}, \mathrm{MCI}, \mathrm{SCD}$ ) as an independent variable, with age as a covariate. The univariate analysis on the memory trial was repeated with the log absolute error of the perception trial as additional covariate. This was to check whether differences between groups and OLMT aspects on the memory trial still existed after controlling for spatial perceptual abilities.

Due to non-normality of the data, even after transformation, the z-scores' VT trials were analyzed with four nonparametric Kruskal-Wallis tests with group as the independent variable and scene recognition, route continuation, temporal order score and distance comparison scores as dependent variables. Post-hoc nonparametric Mann-Whitney pairwise comparisons were performed with a Bonferroni correction.

Spearman correlation coefficients were calculated for association between the six cognitive domains and the experimental OLMT and VT trials. For the OLMT test, two composite scores were calculated for the perception and memory trial, based on the mean of the absolute error rates and best-fit scores.

\section{Results}

\subsection{Demographics}

Demographic data for patients with mild AD dementia, $\mathrm{MCI}$ and SCD are shown in Table 1. Patients with MCI were older than participants with SCD $(p=0.01)$. Nine out of twenty-one patients with mild AD dementia were younger than 65. All groups differed on MMSE and CDR $(p<0.05)$. There were no differences in educational level.

Table 1. Demographic data (mean + standard deviation).

\begin{tabular}{cccc}
\hline & SCD $(\boldsymbol{n}=\mathbf{2 1 )}$ & MCI $(\boldsymbol{n = 2 2 )}$ & $\begin{array}{c}\text { (Mild) AD Dementia } \\
(\boldsymbol{n}=\mathbf{2 1})\end{array}$ \\
\hline Age & $62.2 \pm 8.9^{\mathrm{b}}$ & $69.6 \pm 8.3^{\mathrm{a}}$ & $66.9 \pm 6.9$ \\
[Age range] & $(39-75)$ & $(52-81)$ & $(57-82)$ \\
Women, $n(\%)$ & $10(47.6 \%)$ & $10(45.5 \%)$ & $10(47.6 \%)$ \\
Educational level * & $5.7 \pm 1.2$ & $5.1 \pm 1.4$ & $5.3 \pm 1.3$ \\
Mini-Mental State Examination & $29.1 \pm 1.1^{\mathrm{bc}}$ & $26.1 \pm 2.8^{\mathrm{ac}}$ & $22.8 \pm 5.1^{\mathrm{ab}}$ \\
Clinical Dementia Rating scale & $0.1 \pm 0.2^{\mathrm{bc}}$ & $0.50 \pm 0.00^{\mathrm{ac}}$ & $0.9 \pm 0.2^{\mathrm{ab}}$ \\
\hline
\end{tabular}

Abbreviations: SCD = Subjective Cognitive Decline; MCI = Mild Cognitive Impairment; AD = Alzheimer's disease; ${ }^{a}$ Significant difference at $p<0.05$ with SCD; ${ }^{\mathrm{b}}$ significant difference at $p<0.05$ with $\mathrm{MCI}$; ${ }^{\mathrm{c}}$ significant difference at $p<0.05$ with $\mathrm{AD}$. * Dutch educational system categorized into levels from $1=5$ less than 6 years of primary education to $7=5$ academic schooling [57].

\subsection{Object Location Memory}

\subsubsection{Perception Trial}

Table 2 shows mean z-scores on the OLMT perception and memory trial (see Appendix A for raw data). The SCD group has been left out as they had means of zero and standard deviations of 1 by definition. There was a significant effect of group on the log mean absolute error rates $\left(\mathrm{F}(2,58)=5.0, p=0.01, \eta^{2}=0.15\right)$ and log mean best-fit scores of the 
perception trial $\left(\mathrm{F}(2,58)=4.5, p=0.02, \eta^{2}=0.13\right)$ (Figure 1). Post-hoc Bonferroni tests revealed that patients with $\mathrm{AD}$ dementia had higher mean absolute error rates and best-fit scores than participants with SCD $(p<0.05)$. There was no difference between patients with $\mathrm{MCI}$ and mild $\mathrm{AD}$ dementia or between patients with $\mathrm{MCI}$ and participants with SCD.

Table 2. Mean z-scores and standard deviations on the OLMT and VT tests.

\begin{tabular}{|c|c|c|c|c|}
\hline & $n$ & MCI & $n$ & (Mild) AD Dementia \\
\hline \multicolumn{5}{|l|}{ Object location memory } \\
\hline Perception-absolute error & 22 & $-0.33 \pm 0.99$ & 19 & $-1.19 \pm 1.80 * * a$ \\
\hline Perception-best fit & 22 & $-0.33 \pm 0.99$ & 19 & $-0.98 \pm-1.36^{* * a}$ \\
\hline Memory-absolute error & 20 & $-1.81 \pm 0.92 * * a$ & 17 & $-2.51 \pm 1.15^{* * a}$ \\
\hline Memory-best fit & 20 & $-1.47 \pm 1.19 * * a$ & 17 & $-2.68 \pm 2.45^{* * a}$ \\
\hline \multicolumn{5}{|l|}{ Virtual Tübingen } \\
\hline Scene recognition & 22 & $-1.37 \pm 1.25 * * a$ & 21 & $-1.14 \pm 0.73 * * a$ \\
\hline Route continuation & 22 & $-1.21 \pm 1.07 * * a$ & 21 & $-1.44 \pm 1.13^{* * a}$ \\
\hline Route ordering & 21 & $-0.82 \pm 0.78^{* * a}$ & 20 & $-0.37 \pm 0.82$ \\
\hline Distance comparison & 21 & $-0.49 \pm 0.90$ & 19 & $-1.15 \pm 1.53 *$ \\
\hline
\end{tabular}

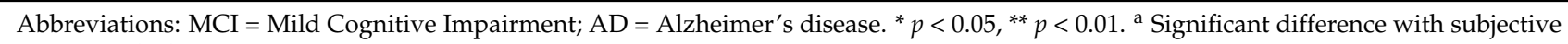
cognitive decline group.

\subsubsection{Memory Trial}

There was a significant main effect of group on the log mean absolute error rates $\left(\mathrm{F}(2,55)=33.54, p<0.01, \eta^{2}=0.55\right)$ and $\log$ mean best-fit scores of the memory trial $\left(\mathrm{F}(2,55)=15.02, p<0.01, \eta^{2}=0.36\right)$ (Figure 3). Post-hoc Bonferroni tests revealed that patients with $\mathrm{AD}$ dementia and $\mathrm{MCI}$ had higher mean absolute error rates and best-fit scores than participants with SCD (all $p<0.01$ ) (see Appendix A for raw data). There were no differences between patients with $\mathrm{MCI}$ and mild AD dementia $(p=0.56)$. After adding the mean absolute error score or best-fit scores on the perception trial as a covariate to the analysis, the effect of group remained significant on the log mean absolute error rates $(\mathrm{F}(2,54)=28.70, p<0.01)$ and mean best-fit scores $(\mathrm{F}(2,54)=12.60, p<0.01)$ of the memory trial. Post-hoc Bonferroni tests revealed that patients with mild AD dementia and MCI had higher mean absolute error rates and best-fit scores than controls (all $p<0.01)$, but there were no differences between patients with mild AD dementia and $\mathrm{MCI}(p=0.81)$.

\subsection{Virtual Tübingen Test}

There was a difference between groups in the number of correct items on the scene recognition task $(\mathrm{H}(2)=16.30, p<0.01)$, the route continuation task $(\mathrm{H}(2)=16.80, p<0.01)$, the route ordering task $(\mathrm{H}(2)=6.51, p=0.04)$ and the distance comparison task $(\mathrm{H}(2)=8.47$, $p=0.01$ ) (Figure 3) (see Appendix A for raw data). Post-hoc Mann-Whitney tests revealed that patients with mild AD dementia and MCI performed worse than participants with SCD on the scene recognition and route continuation tasks $(p<0.01)$. Patients with MCI performed worse on the route ordering task $(p=0.03)$. Patients with mild AD dementia showed a trend towards worse performance on the distance comparison task $(p=0.03)$, but this did not survive multiple comparisons correction. There were no differences on any of the tasks between patients with $\mathrm{MCI}$ and $\mathrm{AD}$ dementia. 


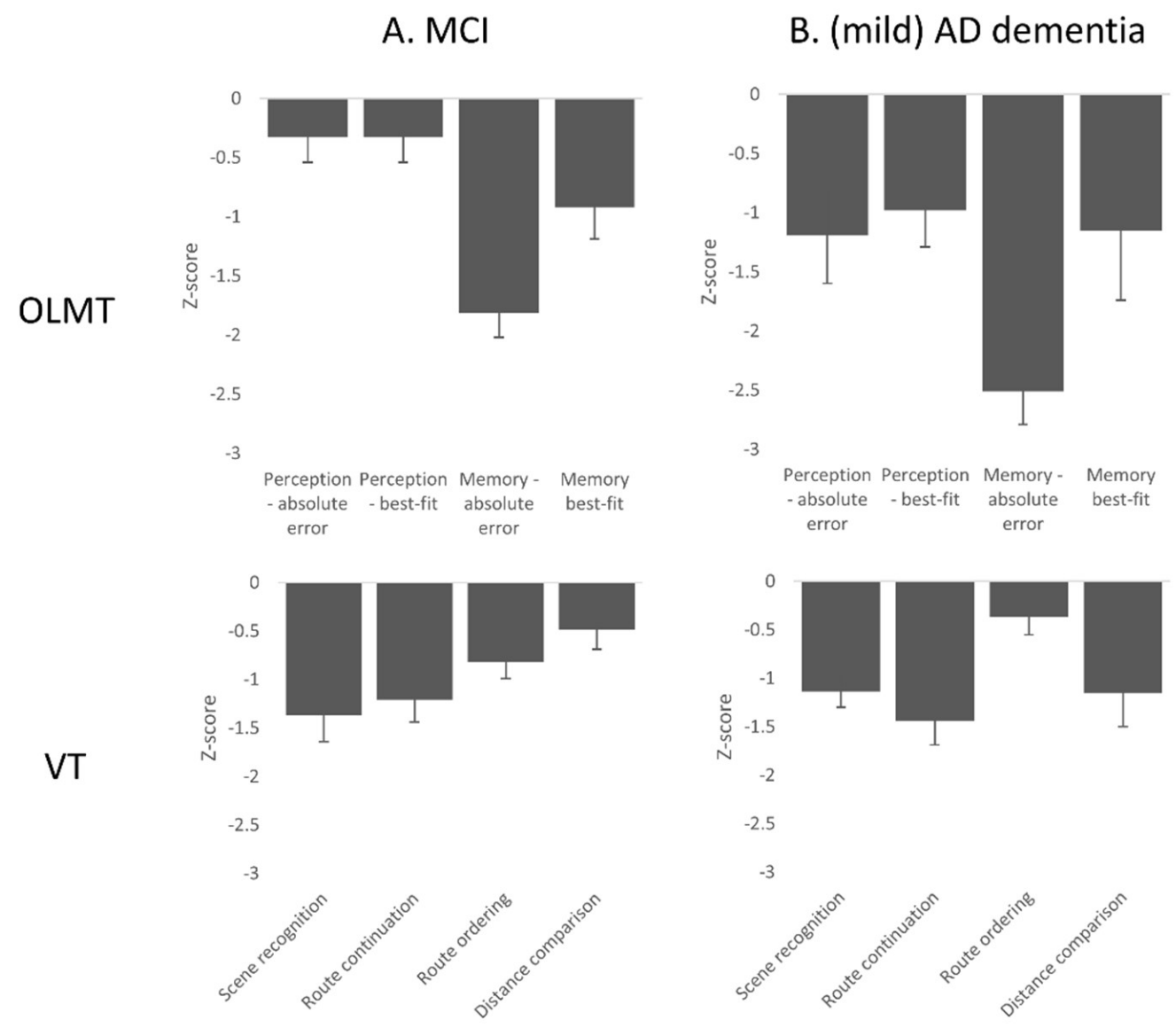

Figure 3. Bar plot of the means and standard errors on the OLMT and VT tasks for (A) patients with $\mathrm{MCI}$, and (B) patients with mild AD dementia. Abbreviations: $\mathrm{MCI}=$ Mild Cognitive Impairment; $\mathrm{AD}=$ Alzheimer's Disease.

\subsection{Correlational Analyses}

Table 3 shows the correlation coefficients between six neuropsychological domains and the OLMT and VT tasks. The route continuation test had a weak to moderate association with the memory domain score $(\mathrm{r}(64)=0.40, p<0.01)$. The temporal route ordering task had a weak to moderate association with attention $(\mathrm{r}(64)=0.33, p<0.05)$. The other VT tasks and the perception and memory trials of the OLMT had no significant correlation with any of the cognitive domains.

Table 3. Spearman correlation coefficients between composite neuropsychological domain scores and the OLMT and VT test scores.

\begin{tabular}{ccccccc}
\hline & Memory & Attention & Executive & Language & Visuospatial & Apraxia \\
\hline & \multicolumn{7}{c}{ Object location memory } \\
Perception & 0.25 & 0.15 & 0.23 & 0.11 & 0.06 & 0.09 \\
Memory & 0.02 & 0.13 & 0.00 & -0.04 & 0.23 & -0.06 \\
& \multicolumn{7}{c}{ Virtual Tübingen } & & \\
Scene recognition & 0.26 & 0.12 & 0.19 & 0.11 & 0.04 & 0.03 \\
Route continuation & $0.40^{* *}$ & 0.21 & 0.18 & 0.19 & 0.08 & -0.00 \\
Temporal route ordering & 0.21 & $0.33 *$ & 0.15 & 0.26 & 0.15 & 0.20 \\
Distance comparison & -0.28 & 0.11 & 0.16 & 0.12 & 0.03 & 0.30 \\
\hline
\end{tabular}

$$
{ }^{*} p<0.05,{ }^{* *} p<0.01 \text {. }
$$




\section{Discussion}

The aim of the present study was to evaluate the differential ability of a short digital spatial memory test in patients with mild AD dementia, MCI and SCD. Our main findings are that both patients with mild AD dementia and $\mathrm{MCI}$ were impaired on object location memory and spatial navigation. In addition, there was little to no relation between the OLMT and VT tests and other cognitive domains, suggesting that performance on these tests reflects a different cognitive construct than is currently used in the standard diagnostic work-up. These results indicate that the short digital spatial memory test battery can detect object location memory and navigation impairment in patients with mild AD dementia and MCI, and therefore could be a valuable addition to the standard neuropsychological protocol in memory clinics.

Object location memory was equally impaired in patients with AD dementia and MCI compared to the SCD group. These findings expand on previous results showing that object location memory can be used to discriminate patients with AD dementia and MCI from healthy older individuals [43,58]. Lesion studies have shown that the hippocampus and parietal cortex play an important role in the binding of objects to locations in memory [59-68], and atrophy in these areas has consistently been found in both patients with MCI and AD dementia [13]. Notably, patients with AD dementia also showed impairment on the OLMT perception task. Visuospatial impairment has been reported previously in patients with AD dementia; however, this is seen more often in patients with an early-onset (before the age of 65) phenotype [69]. As $~ 40 \%$ of patients had an early-onset phenotype of AD dementia, this might have influenced our results. However, after adding the perception trial as a covariate to the analysis of the memory trial, patients with AD dementia and MCI still performed significantly worse on the memory task compared to the SCD group, suggesting that impairment stems from pure memory deficits.

Scene recognition was impaired in both patients with mild AD dementia and MCI, compared to the SCD group. This is unsurprising, as scene recognition has been previously associated with the parahippocampal cortex [59,68,70-72], an area that has been shown to deteriorate in the early stages of AD dementia, but also MCI [73,74]. Similarly, route continuation was also impaired in both patients with mild AD dementia and MCI compared to participants with SCD. Route continuation in the current study is a measure for route learning/egocentric navigation, and impairment on such tasks in AD dementia and MCI has been associated with a parieto-frontal network, including the frontal gyrus, parietal sulcus and the anterior cingulate cortex [75,76]. Indeed, previous studies have shown severe impairments in scene recognition, remembering turns at decision points and recalling the temporal order of routes in both patients with AD dementia and MCI. Furthermore, some of these studies have found that route continuation and route ordering are impaired in both patients with AD dementia and MCI, to the same extent [11,14,24,27,29,33,42,61,77].

Surprisingly, we found impairment on temporal route ordering in patients with $\mathrm{MCI}$, but not patients with mild AD dementia. Likewise, patients with MCI were not impaired on the distance comparison task, and in patients with $\mathrm{AD}$ dementia, a difference compared to SCD did not survive correction for multiple comparisons. Both temporal order memory, from an egocentric reference frame, and spatial navigation tasks, from an allocentric reference frame, such as the distance comparison task, have been associated with the hippocampus [78,79] and parietal areas in patients with MCI and AD dementia [80]. Patients in the symptomatic stage should be especially impaired on tasks that are dependent on these areas, such as temporal order memory and distance comparison. Other studies have shown specific impairment in allocentric navigation already at the MCI stage [41]. Possible reasons for why we did not find the expected differences are small sample sizes, a small number of test items in the route ordering and distance comparison task (i.e., six and three, respectively) or a difference in the strategies used by patients. It could be that temporal order memory was impaired to such an extent in patients with AD dementia that patients relied, for example, on a primacy/recency effect strategy, where only items that were seen earliest/latest in the route were remembered correctly. As there was a fixed 
starting position (i.e., all patients were presented the images in the same order), and several patients with AD dementia claimed to remember nothing and left the images as they were initially presented, this possibly resulted in them having a higher temporal route ordering score than patients who did attempt to re-order the images. Yet, there was no significant difference between patients with AD dementia and MCI (who were impaired on temporal route ordering) suggesting that there is a trend towards impairment on temporal order memory in patients with mild AD dementia.

Another explanation for why we did not find impairment on the distance comparison task in patients with MCI could be that we did not differentiate between amnestic, nonamnestic and multi-domain MCI. Previous studies investigating the distinction between egocentric and allocentric spatial navigation in MCI differentiated between subtypes of MCI $[26,28,38]$. For example, Hort and colleagues (2007) divided patients with MCI in an amnestic type, a multi-domain type and a non-amnestic type. The results showed that patients with amnestic MCI were especially impaired on the allocentric test compared to the patients with non-amnestic MCI [26]. This is unsurprising, given that patients with amnestic MCI are identified as those most likely to convert to symptomatic AD, whereas most other forms remain stable, revert to a normal stage or convert to another form of dementia [81]. Patients with MCI included in the current study were not stratified according to phenotype during the diagnosis setting, and so the inclusion of all three types could have influenced our results. However, as patients with MCI were significantly impaired on the hippocampus-dependent route ordering task, indicating that patients with amnestic MCI were representative of the sample, it seems more likely that the absence of impairment on the distance comparison task was due to the low number of test items, and a task with more items might be more sensitive.

There were no correlations found between the OLMT tests and any of the measured cognitive domains that are part of standard neuropsychological clinical assessment. There was a weak to moderate correlation between the route continuation task and memory, and interestingly, also between the temporal route ordering task and attention scores. A possible explanation for the latter is that the temporal route ordering task also depends on frontal brain areas, such as the prefrontal cortex. Several previous studies have demonstrated the involvement of prefrontal areas in spatial navigation planning [82-84], and these areas also play a critical role in attentional processes [85]. The fact that only very few weak to moderate correlations with other neuropsychological domains were found suggests that the OLMT and VT tests measure cognitive constructs that are not well represented within routine neuropsychological assessment. This indicates the importance of introducing spatial memory tests in clinical practice.

There are several limitations to this study, including small sample sizes, not-agematched groups and the lack of neuroimaging and CSF biomarker information. Patients with MCI have often been shown to possess neuropathological signs of AD and progress to AD dementia at a faster rate than cognitively healthy individuals [86]. MCI patients with underlying AD pathology exhibit the amnestic phenotype more often than patients with non-amnestic MCI [87], but we included all patients with MCI regardless of phenotype. Similarly, participants with SCD had cognitive complaints, which motivated their consultation at the memory clinic, thereby meeting the SCD plus criteria and having a higher risk of having preclinical AD [86]. Although both MCI and SCD are heterogeneous syndromes, and not all individuals will develop AD dementia, using participants with SCD as a control group and the non-specificity of MCI phenotypes (i.e., amnestic, nonamnestic and multi-domain) are drawbacks in this study. In addition, our speculations about the potential neural mechanisms that underlie the differences between patient groups cannot be corroborated in the absence of neuroimaging data. Another limitation of this study is that participants with SCD were significantly younger than patients with MCI, including two participants younger than 50. Age-related decline has been found in spatial memory and navigation studies in healthy older individuals [88,89], and including young participants in the SCD group may have affected the results. Group differences should 
therefore be interpreted cautiously, especially in the VT test, as those were not corrected for age due to the nonparametric statistical approach. Future research should focus on validating these tests in a larger cohort of patients, taking into account biomarker information on underlying AD pathology, correlating with brain imaging data and comparing performance with a population of cognitively healthy older adults without underlying AD pathology. In addition, longitudinal follow-up is necessary to investigate the potential of the OLMT and VT test as cognitive markers in AD development. The development of short, computer-generated and yet sensitive spatial memory tests is important if we are to introduce tests in clinical practice that reflect real-world performance, but at the same time are easy to administer.

In conclusion, object location memory and spatial navigation were found to be clearly affected in patients with $\mathrm{MCI}$ and mild $\mathrm{AD}$ dementia. Neither object location memory nor navigation assessments are generally performed in current clinical practice. Given the importance of these functions and the frequency of deficits, evaluation of spatial memory abilities should be included in standard neuropsychological examination in older adults. Yet, at present, no standardized spatial memory measures are in use. The Object Relocation program and virtual reality tests offer a viable opportunity for this purpose. This study confirms that object location memory and spatial navigation are impaired in mild AD dementia and $\mathrm{MCI}$, and underlines that assessment of these processes should be incorporated in the standard diagnostic work-up for older adults.

Author Contributions: Conceptualization, J.M.P., I.J.M.v.d.H., W.M.v.d.F. and A.P.; Data curation, J.M.P., A.E.L., Y.A.L.P. and W.M.v.d.F.; Formal analysis, J.M.P.; Methodology, I.J.M.v.d.H. and A.P.; Project administration, A.E.L.; Resources, I.J.M.v.d.H., A.E.L., Y.A.L.P., W.M.v.d.F. and A.P.; Software, I.J.M.v.d.H. and A.P.; Supervision, I.J.M.v.d.H., A.E.L., W.M.v.d.F. and A.P.; Writing-original draft, J.M.P.; Writing-review and editing, J.M.P., I.J.M.v.d.H., A.E.L., Y.A.L.P., W.M.v.d.F. and A.P. All authors have read and agreed to the published version of the manuscript.

Funding: This research received no external funding.

Institutional Review Board Statement: The study was conducted according to the guidelines of the Declaration of Helsinki, and approved by the Ethics Committee of the AMSTERDAM UNIVERSITY MEDICAL CENTER.

Informed Consent Statement: Informed consent was obtained from all subjects involved in the study.

Data Availability Statement: Data will be shared upon request.

Acknowledgments: We thank all participants for enrollment in this study.

Conflicts of Interest: The authors declare no conflict of interest.

\section{Appendix A}

Table A1. Mean and standard deviation of the raw scores on the ORT and VT tests.

\begin{tabular}{cccc}
\hline & MCI & (Mild) AD Dementia & SCD \\
\hline Object location memory & & & \\
Perception-absolute error & $138.0 \pm 13.8$ & $171.8 \pm 13.8$ & $124.6 \pm 13.1$ \\
Perception-best fit & $138.0 \pm 13.8$ & $169.8 \pm 13.4$ & $124.6 \pm 13.1$ \\
Memory-absolute error & $499.8 \pm 27.0$ & $629.2 \pm 31.3$ & $266.0 \pm 29.5$ \\
Memory-best fit & $255.8 \pm 12.2$ & $313.1 \pm 27.1$ & $190.3 \pm 9.6$ \\
Virtual Tübingen & & & \\
Scene recognition & $8.4 \pm 0.3$ & $8.8 \pm 0.2$ & $9.9 \pm 0.2$ \\
Route continuation & $3.2 \pm 0.2$ & $2.9 \pm 0.3$ & $4.4 \pm 0.2$ \\
Route ordering & $2.5 \pm 0.2$ & $3.1 \pm 0.2$ & $3.4 \pm 0.2$ \\
Distance comparison & $3.6 \pm 0.2$ & $3.2 \pm 0.4$ & $4.2 \pm 0.2$ \\
\hline
\end{tabular}

Abbreviations: MCI = Mild Cognitive Impairment; AD = Alzheimer's disease. 


\section{References}

1. Alzheimer's Association. 2015 Alzheimer's disease facts and figures. Alzheimer's Dement. 2015, 11, 332-384. [CrossRef]

2. Jessen, F.; Amariglio, R.E.; van Boxtel, M.; Breteler, M.; Ceccaldi, M.; Chételat, G.; Dubois, B.; Dufouil, C.; Ellis, K.A.; van der Flier, W.M.; et al. A conceptual framework for research on subjective cognitive decline in preclinical Alzheimer's disease. Alzheimer's Dement. 2014, 10, 844-852. [CrossRef]

3. Albert, M.S.; DeKosky, S.T.; Dickson, D.; Dubois, B.; Feldman, H.H.; Fox, N.C.; Gamst, A.; Holtzman, D.M.; Jagust, W.J.; Petersen, R.C.; et al. The diagnosis of mild cognitive impairment due to Alzheimer's disease: Recommendations from the National Institute on Aging-Alzheimer's Association workgroups on diagnostic guidelines for Alzheimer's disease. Alzheimer's Dement. 2011, 7, 270-279. [CrossRef]

4. McKhann, G.M.; Knopman, D.S.; Chertkow, H.; Hyman, B.T.; Jack, C.R., Jr.; Kawas, C.H.; Klunk, W.E.; Koroshetz, W.J.; Manly, J.J.; Mayeux, R. The diagnosis of Dementia due to Alzheimer's disease: Recommendations from the National Institute on Aging-Alzheimer's Association workgroups on diagnostic guidelines for Alzheimer's disease. Alzheimer's Dement. 2011, 7, 263-269. [CrossRef]

5. Dubois, B.; Feldman, H.; Jacova, C.; Hampel, H.; Molinuevo, J.L.; Blennow, K.; DeKosky, S.; Gauthier, S.; Selkoe, D.; Bateman, R.; et al. Advancing research diagnostic criteria for Alzheimer's disease: The IWG-2 criteria. Lancet Neurol. 2014, 13, 614-629. [CrossRef]

6. Logsdon, R.G.; Teri, L.; McCurry, S.M.; Gibbons, L.E.; Kukull, W.A.; Larson, E.B. Wandering: A significant problem among community-residing individuals with Alzheimer's disease. J. Gerontol. Ser. B 1998, 53, P294-P299. [CrossRef]

7. Rolland, Y.; Gilette-Guyonnet, S.; Nourhashémi, F.; Andrieu, S.; Cantet, C.; Payoux, P.; Ousset, P.J.; Vellas, B. Wandering and Alzheimer's type disease. Descriptive study. REAL. FR research program on Alzheimer's disease and management. Rev. Med. Interne 2003, 24, 333-338. [CrossRef]

8. Davis, R.L.; Ohman, J.M. Driving in early-stage Alzheimer's Disease. An integrative review of the literature. Res. Gerontol. Nurs. 2017, 10, 86-100. [CrossRef] [PubMed]

9. Uc, E.; Rizzo, M.; Anderson, S.W.; Shi, Q.; Dawson, J.D. Driver route-following and safety errors in early Alzheimer disease. Neurology 2004, 63, 832-837. [CrossRef] [PubMed]

10. Postma, A.; van der Ham, I.J.M. Neuropsychology of Space: Spatial Functions of the Human Brain. Available online: http: // site.ebrary.com/id/11269954 (accessed on 6 October 2021).

11. Deipolyi, A.; Rankin, K.P.; Mucke, L.; Miller, B.L.; Gorno-Tempini, M.L. Spatial cognition and the human navigation network in AD and MCI. Neurology 2007, 69, 986-997. [CrossRef]

12. Van Der Ham, I.J.; Van Zandvoort, M.J.; Meilinger, T.; Bosch, S.E.; Kant, N.; Postma, A. Spatial and temporal aspects of navigation in two neurological patients. NeuroReport 2010, 21, 685-689. [CrossRef] [PubMed]

13. Braak, H.; Braak, E. Neuropathological stageing of Alzheimer-related changes. Acta Neuropathol. 1991, 82, 239-259. [CrossRef] [PubMed]

14. Cushman, L.A.; Stein, K.; Duffy, C.J. Detecting navigational deficits in cognitive aging and Alzheimer disease using virtual reality. Neurology 2008, 71, 888-895. [CrossRef]

15. Coughlan, G.; Laczó, J.; Hort, J.; Minihane, A.-M.; Hornberger, M. Spatial navigation deficits—Overlooked cognitive marker for preclinical Alzheimer disease? Nat. Rev. Neurol. 2018, 14, 496-506. [CrossRef]

16. Tangen, G.G.; Engedal, K.; Bergland, A.; Moger, T.A.; Hansson, O.; Mengshoel, A.M. Spatial navigation measured by the Floor Maze Test in patients with subjective cognitive impairment, mild cognitive impairment, and mild Alzheimer's disease. Int. Psychogeriatr. 2015, 27, 1401-1409. [CrossRef]

17. Vandenberg, S.G.; Kuse, A.R. Mental Rotations, a Group Test of Three-Dimensional Spatial Visualization. Percept. Mot. Ski. 1978, 47, 599-604. [CrossRef] [PubMed]

18. Kessels, R.P.; Nys, G.M.; Brands, A.M.; Berg, E.V.D.; Zandvoort, V.M.J. The modified Location Learning Test: Norms for the assessment of spatial memory function in neuropsychological patients. Arch. Clin. Neuropsychol. 2006, 21, 841-846. [CrossRef]

19. Kessels, R.P.C.; Van Zandvoort, M.J.E.; Postma, A.; Kappelle, L.J.; de Haan, E. The Corsi Block-Tapping Task: Standardization and Normative Data. Appl. Neuropsychol. 2000, 7, 252-258. [CrossRef]

20. Money, J.; Alexander, D.; Walker, H.T. A Standardized Road-Map Test of Direction Sense: Manual; Johns Hopkins Press: Baltimore, MD, USA, 1965.

21. Schinazi, V.R.; Nardi, D.; Newcombe, N.S.; Shipley, T.F.; Epstein, R.A. Hippocampal size predicts rapid learning of a cognitive map in humans. Hippocampus 2013, 23, 515-528. [CrossRef]

22. Mapstone, M.; Steffenella, T.M.; Duffy, C.J. A visuospatial variant of mild cognitive impairment: Getting lost between aging and AD. Neurology 2003, 60, 802-808. [CrossRef] [PubMed]

23. Laczó, J.; Vlček, K.; Vyhnálek, M.; Vajnerová, O.; Ort, M.; Holmerová, I.; Tolar, M.; Andel, R.; Bojar, M.; Hort, J. Spatial navigation testing discriminates two types of amnestic mild cognitive impairment. Behav. Brain Res. 2009, 202, 252-259. [CrossRef]

24. Benke, T.; Karner, E.; Petermichl, S.; Prantner, V.; Kemmler, G. Neuropsychological Deficits Associated with Route Learning in Alzheimer Disease, MCI, and Normal Aging. Alzheimer Dis. Assoc. Disord. 2014, 28, 162-167. [CrossRef] [PubMed]

25. Cherrier, M.M.; Mendez, M.; Perryman, K. Route learning performance in Alzheimer disease patients. Cogn. Behav. Neurol. 2001, 14, 159-168. 
26. Hort, J.; Laczo, J.; Vyhnalek, M.; Bojar, M.; Bures, J.; Vlcek, K. Spatial navigation deficit in amnestic mild cognitive impairment. Proc. Natl. Acad. Sci. USA 2007, 104, 4042-4047. [CrossRef] [PubMed]

27. Pai, M.-C.; Jan, S.-S. Have I Been Here? Sense of Location in People with Alzheimer's Disease. Front. Aging Neurosci. 2020, $12,441$. [CrossRef] [PubMed]

28. Schöberl, F.; Pradhan, C.; Irving, S.; Buerger, K.; Xiong, G.; Kugler, G.; Kohlbecher, S.; Engmann, J.; Werner, P.; Brendel, M.; et al. Real-space navigation testing differentiates between amyloid-positive and -negative aMCI. Neurology 2020, 94, e861-e873. [CrossRef]

29. Bellassen, V.; Iglói, K.; De Souza, L.C.; Dubois, B.; Rondi-Reig, L. Temporal Order Memory Assessed during Spatiotemporal Navigation as a Behavioral Cognitive Marker for Differential Alzheimer's Disease Diagnosis. J. Neurosci. 2012, 32, $1942-1952$. [CrossRef]

30. Coutrot, A.; Schmidt, S.; Pittman, J.; Hong, L.; Wiener, J.M.; Hölscher, C.; Dalton, R.C.; Hornberger, M.; Spiers, H.J. Virtual navigation tested on a mobile app (sea hero quest) is predictive of real-world navigation performance: Preliminary data. bioRxiv 2018, 305433. [CrossRef]

31. Davis, R.; Ohman, J.M.; Weisbeck, C. Salient Cues and Wayfinding in Alzheimer's Disease within a Virtual Senior Residence. Environ. Behav. 2017, 49, 1038-1065. [CrossRef]

32. Migo, E.; O’Daly, O.; Mitterschiffthaler, M.; Antonova, E.; Dawson, G.; Dourish, C.; Craig, K.; Simmons, A.; Wilcock, G.; McCulloch, E.; et al. Investigating virtual reality navigation in amnestic mild cognitive impairment using fMRI. Aging Neuropsychol. Cogn. 2016, 23, 196-217. [CrossRef]

33. Pengas, G.; Williams, G.B.; Acosta-Cabronero, J.; Ash, T.W.J.; Hong, Y.T.; Izquierdo-Garcia, D.; Fryer, T.D.; Hodges, J.R.; Nestor, P.J. The relationship of topographical memory performance to regional neurodegeneration in Alzheimer's disease. Front. Aging Neurosci. 2012, 4, 17. [CrossRef] [PubMed]

34. Piper, B.J.; Acevedo, S.F.; Craytor, M.J.; Murray, P.W.; Raber, J. The use and validation of the spatial navigation Memory Island test in primary school children. Behav. Brain Res. 2010, 210, 257-262. [CrossRef] [PubMed]

35. Ritter, E.; Després, O.; Monsch, A.U.; Manning, L. Topographical recognition memory sensitive to amnestic mild cognitive impairment but not to depression. Int. J. Geriatr. Psychiatry 2006, 21, 924-929. [CrossRef] [PubMed]

36. Weniger, G.; Ruhleder, M.; Lange, C.; Wolf, S.; Irle, E. Egocentric and allocentric memory as assessed by virtual reality in individuals with amnestic mild cognitive impairment. Neuropsychologia 2011, 49, 518-527. [CrossRef]

37. Wu, Y.-F.; Wu, W.-B.; Liu, Q.-P.; He, W.-W.; Ding, H.; Nedelska, Z.; Hort, J.; Zhang, B.; Xu, Y. Presence of lacunar infarctions is associated with the spatial navigation impairment in patients with mild cognitive impairment: A DTI study. Oncotarget 2016, 7, 78310-78319. [CrossRef]

38. Howett, D.; Castegnaro, A.; Krzywicka, K.; Hagman, J.; Marchment, D.; Henson, R.; Rio, M.; King, J.A.; Burgess, N.; Chan, D. Differentiation of mild cognitive impairment using an entorhinal cortex-based test of virtual reality navigation. Brain 2019, 142, 1751-1766. [CrossRef] [PubMed]

39. Kalová, E.; Vlček, K.; Jarolímová, E.; Bureš, J. Allothetic orientation and sequential ordering of places is impaired in early stages of Alzheimer's disease: Corresponding results in real space tests and computer tests. Behav. Brain Res. 2005, 159, 175-186. [CrossRef]

40. Laczó, J.; Andel, R.; Vlček, K.; Macoška, V.; Vyhnálek, M.; Tolar, M.; Bojar, M.; Hort, J. Spatial Navigation and APOE in Amnestic Mild Cognitive Impairment. Neurodegener. Dis. 2011, 8, 169-177. [CrossRef]

41. Lithfous, S.; Dufour, A.; Després, O. Spatial navigation in normal aging and the prodromal stage of Alzheimer's disease: Insights from imaging and behavioral studies. Ageing Res. Rev. 2013, 12, 201-213. [CrossRef]

42. Levine, T.F.; Allison, S.L.; Stojanovic, M.; Fagan, A.M.; Morris, J.C.; Head, D. Spatial navigation ability predicts progression of dementia symptomatology. Alzheimer's Dement. 2020, 16, 491-500. [CrossRef] [PubMed]

43. Van Asselen, M.; Kessels, R.P.; Frijns, C.J.; Kappelle, L.J.; Neggers, S.F.; Postma, A. Object-location memory: A lesion-behavior mapping study in stroke patients. Brain Cogn. 2009, 71, 287-294. [CrossRef] [PubMed]

44. Claessen, M.H.; van der Ham, I.J. Classification of navigation impairment: A systematic review of neuropsychological case studies. Neurosci. Biobehav. Rev. 2017, 73, 81-97. [CrossRef] [PubMed]

45. van der Flier, W.M.; Pijnenburg, Y.A.; Prins, N.; Lemstra, A.W.; Bouwman, F.H.; Teunissen, C.E.; van Berckel, B.N.; Stam, C.J.; Barkhof, F.; Visser, P.J.; et al. Optimizing Patient Care and Research: The Amsterdam Dementia Cohort. J. Alzheimer's Dis. 2014, 41, 313-327. [CrossRef] [PubMed]

46. van der Flier, W.M.; Scheltens, P. Amsterdam dementia cohort: Performing research to optimize care. J. Alzheimer's Dis. 2018, 62, 1091-1111. [CrossRef] [PubMed]

47. Postma, A.; De Haan, E.H. What was where? Memory for object locations. Q. J. Exp. Psychol. A 1996, 49, 178-199. [CrossRef]

48. Folstein, M.F.; Folstein, S.E.; McHugh, P.R. "Mini-mental state": A practical method for grading the cognitive state of patients for the clinician. J. Psychiatr. Res. 1975, 12, 189-198. [CrossRef]

49. Van der Elst, W.; van Boxtel, M.P.; van Breukelen, G.J.; Jolles, J. Rey's verbal learning test: Normative data for 1855 healthy participants aged 24-81 years and the influence of age, sex, education, and mode of presentation. J. Int. Neuropsychol. Soc. 2005, 11, 290-302. [CrossRef]

50. Lindeboom, J.; Schmand, B.; Tulner, L.; Walstra, G.; Jonker, C. Visual association test to detect early dementia of the Alzheimer type. J. Neurol. Neurosurg. Psychiatry 2002, 73, 126-133. [CrossRef] 
51. Corrigan, J.D.; Hinkeldey, N.S. Relationships between Parts A and B of the Trail Making Test. J. Clin. Psychol. 1987, 43, 402-409. [CrossRef]

52. Van der Elst, W.; van Boxtel, M.P.; van Breukelen, G.J.; Jolles, J. The letter digit substitution test: Normative data for 1858 healthy participants aged 24-81 from the Maastricht Aging Study (MAAS): Influence of age, education, and sex. J. Clin. Exp. Neuropsychol. 2006, 28, 998-1009. [CrossRef]

53. Lindeboom, J.; Matto, D. Digit series and knox cubes as concentration tests for elderly subjects [cijferreeksen en knox blokken als concentratietests voor ouderen]. Tijdschr. Gerontol. Geriatr. 1994, 25, 63-68.

54. Schmand, B.; Groenink, S.C.; Van den Dungen, M. Letter fluency: Psychometric properties and Dutch normative data. Tijdschr. Gerontol. Geriatr. 2008, 39, 64-76. [CrossRef] [PubMed]

55. Van der Elst, W.; van Boxtel, M.P.; van Breukelen, G.J.; Jolles, J. Normative data for the Animal, Profession and Letter M Naming verbal fluency tests for Dutch speaking participants and the effects of age, education, and sex. J. Int. Neuropsychol. Soc. 2006, 12, 80-89. [CrossRef] [PubMed]

56. Quental, N.B.M.; Brucki, S.; Bueno, O.F.A. Visuospatial Function in Early Alzheimer's Disease-The Use of the Visual Object and Space Perception (VOSP) Battery. PLoS ONE 2013, 8, e68398. [CrossRef]

57. Verhage, F. Intelligence and Age: Study with Dutch People Aged 12-77; Van Gorcum: Assen, The Netherlands, 1964. (In Dutch)

58. Tepest, R.; Wang, L.; Csernansky, J.G.; Neubert, P.; Heun, R.; Scheef, L.; Jessen, F. Hippocampal Surface Analysis in Subjective Memory Impairment, Mild Cognitive Impairment and Alzheimer's Dementia. Dement. Geriatr. Cogn. Disord. 2008, 26, 323-329. [CrossRef] [PubMed]

59. Bohbot, V.D.; Kalina, M.; Stepankova, K.; Spackova, N.; Petrides, M.; Nadel, L. Spatial memory deficits in patients with lesions to the right hippocampus and to the right parahippocampal cortex. Neuropsychologia 1998, 36, 1217-1238. [CrossRef]

60. Nunn, J.A.; Graydon, F.J.X.; Polkey, C.E.; Morris, R.G. Differential spatial memory impairment after right temporal lobectomy demonstrated using temporal titration. Brain 1999, 122, 47-59. [CrossRef]

61. Smith, M.L.; Milner, B. The role of the right hippocampus in the recall of spatial location. Neuropsychologia 1981, 19, 781-793. [CrossRef]

62. Smith, M.L.; Milner, B. Right hippocampal impairment in the recall of spatial location: Encoding deficit or rapid forgetting? Neuropsychologia 1989, 27, 71-81. [CrossRef]

63. Stepankova, K.; Fenton, A.A.; Pastalkova, E.; Kalina, M.; Bohbot, V.D. Object-location memory impairment in patients with thermal lesions to the right or left hippocampus. Neuropsychologia 2004, 42, 1017-1028. [CrossRef]

64. Maguire, E.A.; Frith, C.; Burgess, N.; Donnett, J.G.; O’Keefe, J. Knowing Where Things Are: Parahippocampal Involvement in Encoding Object Locations in Virtual Large-Scale Space. J. Cogn. Neurosci. 1998, 10, 61-76. [CrossRef]

65. Piekema, C.; Kessels, R.P.; Mars, R.B.; Petersson, K.M.; Fernández, G. The right hippocampus participates in short-term memory maintenance of object-location associations. NeuroImage 2006, 33, 374-382. [CrossRef]

66. Kessels, R.P.C.; Hendriks, M.P.H.; Schouten, J.; van Asselen, M.; Postma, A. Spatial memory deficits in patients after unilateral selective amygdalahippocampectomy. J. Int. Neuropsychol. Soc. 2004, 10, 907-912. [CrossRef] [PubMed]

67. Kessels, R.P.; Kappelle, L.J.; de Haan, E.; Postma, A. Lateralization of spatial-memory processes: Evidence on spatial span, maze learning, and memory for object locations. Neuropsychologia 2002, 40, 1465-1473. [CrossRef]

68. Bohbot, V.D.; Corkin, S. Posterior parahippocampal place learning in H.M. Hippocampus 2007, 17, 863-872. [CrossRef] [PubMed]

69. Koedam, E.L.; Lauffer, V.; van der Vlies, A.E.; van der Flier, W.M.; Scheltens, P.; Pijnenburg, Y.A. Early-versus Late-Onset Alzheimer's Disease: More than Age Alone. J. Alzheimer's Dis. 2010, 19, 1401-1408. [CrossRef]

70. Ruzich, E.; Garcia, C.; Dalal, S.S.; Schneidermann, J.F. Characterizing hippocampal dynamics with MEG: A systematic review and evidence-based guidelines. Hum. Brain Mapp. 2019, 40, 1353-1375. [CrossRef]

71. Rungratsameetaweemana, N.; Squire, L.R. Preserved capacity for scene construction and shifts in perspective after hippocampal lesions. Learn. Mem. 2018, 25, 347-351. [CrossRef]

72. Epstein, R.; Kanwisher, N. A cortical representation of the local visual environment. Nature 1998, 392, 598-601. [CrossRef]

73. Kesslak, J.P.; Nalcioglu, O.; Cotman, C.W. Quantification of magnetic resonance scans for hippocampal and parahippocampal atrophy in Alzheimer's disease. Neurology 1991, 41, 51. [CrossRef]

74. Mitchell, T.W.; Mufson, E.J.; Schneider, J.A.; Cochran, E.J.; Nissanov, J.; Han, L.-Y.; Bienias, J.L.; Lee, V.M.-Y.; Trojanowski, J.Q.; Bennett, D.A.; et al. Parahippocampal tau pathology in healthy aging, mild cognitive impairment, and early Alzheimer's disease. Ann. Neurol. 2002, 51, 182-189. [CrossRef]

75. Luzzi, S.; Cafazzo, V.; Damora, A.; Fabi, K.; Fringuelli, F.M.; Ascoli, G.; Silvestrini, M.; Provinciali, L.; Reverberi, C. The neural correlates of road sign knowledge and route learning in semantic dementia and Alzheimer's disease. J. Neurol. Neurosurg. Psychiatry 2015, 86, 595-602. [CrossRef] [PubMed]

76. Mellet, E.; Bricogne, S.; Tzourio-Mazoyer, N.; Ghaëm, O.; Petit, L.; Zago, L.; Etard, O.; Berthoz, A.; Mazoyer, B.; Denis, M. Neural Correlates of Topographic Mental Exploration: The Impact of Route versus Survey Perspective Learning. NeuroImage 2000, 12, 588-600. [CrossRef]

77. Mitolo, M.; Gardini, S.; Caffarra, P.; Ronconi, L.; Venneri, A.; Pazzaglia, F. Relationship between spatial ability, visuospatial working memory and self-assessed spatial orientation ability: A study in older adults. Cogn. Process. 2015, 16, 165-176. [CrossRef] [PubMed] 
78. Igloi, K.; Doeller, C.F.; Berthoz, A.; Rondi-Reig, L.; Burgess, N. Lateralized human hippocampal activity predicts navigation based on sequence or place memory. Proc. Natl. Acad. Sci. USA 2010, 107, 14466-14471. [CrossRef]

79. Hartley, T.; Lever, C.; Burgess, N.; O'Keefe, J. Space in the brain: How the hippocampal formation supports spatial cognition. Philos. Trans. R. Soc. B Biol. Sci. 2014, 369, 20120510. [CrossRef] [PubMed]

80. Vlček, K.; Laczó, J. Neural correlates of spatial navigation changes in mild cognitive impairment and Alzheimer's disease. Front. Behav. Neurosci. 2014, 8, 89.

81. Yaffe, K.; Petersen, R.C.; Lindquist, K.; Kramer, J.; Miller, B. Subtype of Mild Cognitive Impairment and Progression to Dementia and Death. Dement. Geriatr. Cogn. Disord. 2006, 22, 312-319. [CrossRef]

82. Spiers, H.J.; Maguire, E.A. Thoughts, behaviour, and brain dynamics during navigation in the real world. NeuroImage 2006, 31, 1826-1840. [CrossRef]

83. Spiers, H.J.; Maguire, E.A. A navigational guidance system in the human brain. Hippocampus 2007, 17, 618-626. [CrossRef]

84. Martinet, L.-E.; Sheynikhovich, D.; Benchenane, K.; Arleo, A. Spatial Learning and Action Planning in a Prefrontal Cortical Network Model. PLoS Comput. Biol. 2011, 7, e1002045. [CrossRef] [PubMed]

85. Knight, R.T.; Grabowecky, M.F.; Scabini, D. Role of human prefrontal cortex in attention control. In Epilepsy and the Functional Anatomy of the Frontal Lobe; Jasper, H.H., Riggio, S., Goldman-Rakic, P.S., Eds.; Raven Press: New York, NY, USA, $1995 ;$ pp. 22-26.

86. Sperling, R.A.; Aisen, P.S.; Beckett, L.A.; Bennett, D.A.; Craft, S.; Fagan, A.M.; Iwatsubo, T.; Jack, C.R.; Kaye, J.; Montine, T.J.; et al. Towards defining the preclinical stages of Alzheimer's disease: Recommendations from the National Institute on Aging-Alzheimer's Association work-groups on diagnostic guidelines for Alzheimer's disease. Alzheimer's Dement. 2011, 8, 280-292. [CrossRef] [PubMed]

87. Dubois, B.; Albert, M.L. Amnestic MCI or prodromal Alzheimer's disease? Lancet Neurol. 2004, 3, 246-248. [CrossRef]

88. van der Ham, I.J.M.; Claessen, M.H.G. How age relates to spatial navigation performance: Functional and methodological considerations. Ageing Res. Rev. 2020, 58, 101020. [CrossRef]

89. Li, A.W.; King, J. Spatial memory and navigation in ageing: A systematic review of MRI and fMRI studies in healthy participants. Neurosci. Biobehav. Rev. 2019, 103, 33-49. [CrossRef] 